UNIVERSIDADE ESTADUAL DE FEIRA DE SANTANA

Autorizada pelo Decreto Federal n ${ }^{0} 77.496$ de 27/04/76

PPPGoredenciamento pelo Decreto ${ }^{\circ} 17.228$ de 25/11/2016

PRÓ-REITORIA DE PESQUISA E PÓS-GRADUAÇÃO

COORDENAÇÃO DE INICIAÇÃO CIENTÍFICA

XXIV SEMINÁRIO DE INICIAÇÃO CIENTÍFICA DA UEFS

SEMANA NACIONAL DE CIÊNCIA E TECNOLOGIA - 2020

\title{
PERFIL DE MULHERES VÍTIMAS DE VIOLÊNCIA ATENDIDAS NUMA EMERGÊNCIA PÚBLICA DE FEIRA DE SANTANA - BAHIA
}

$\underline{\text { Fernanda Caetano dos Santos Silva }}{ }^{1}$; Ariane Cedraz Morais ${ }^{2}$

1. Bolsista PIBIC/CNPq, Graduando em Enfermagem, Universidade Estadual de Feira de Santana, e-mail: nanda.caetano.enf@hotmail.com

2. Orientadora, Departamento de Saúde, Universidade Estadual de Feira de Santana Mestre em Enfermagem, Professora Assistente B da UEFS, enfarianecedraz@hotmail.com

PALAVRAS-CHAVE: Saúde da Mulher; Violência contra mulher; Gênero.

\section{INTRODUÇÃO}

A violência contra a mulher atinge, no Brasil, todas as classes e segmentos sociais, operando numa base de discriminação e abuso sobre as diferenças, quais sejam de gênero, de classe social, de raça, econômica e geracional, sujeitando as mulheres à situações como fome, tortura, humilhação e mutilação. Em grande maioria estes abusos são perpetrados dentro do próprio espaço doméstico, onde a vítima quase sempre é violentada por pessoas do seu convívio, ou alguém conhecido, como companheiros, padrastos, namorados, vizinhos, entre outros.

Esse pressente trabalho, portanto, tem como justificativa realizar um levantamento de casos de mulheres violentadas atendidas num serviço de urgência e emergência de Feira de Santana- Bahia, ressaltando a importância e destaque das ações desempenhadas por este hospital, sendo referência na saúde pública do município (Sistema Único de Saúde) além de integrar a Rede de Atenção à Mulher Vítima de Violência, prestando atendimentos às mulheres vítimas de violências.

Além disso, este estudo tem o intuito de despertar os profissionais de saúde para a problemática da violência contra mulher, muitas vezes despercebidas, e incentivar a prática de uma atuação que contemple e contabilize a violência nos diagnósticos realizados, aprimorando, assim, a eficácia das ações de saúde, além de assegurar que estas mulheres, vítimas, não sejam re-vitimizadas por estes serviços; ainda colaborar com a formação dos 
estudantes de graduação em saúde desta universidade ao compreender a atuação da Rede de Atenção ás pessoas vítimas de violência, protocolos e acolhimentos específicos.

Apresentando como objetivo principal: Avaliar o perfil de mulheres em vivências de violências atendidas em uma emergência pública de Feira de Santana - Bahia entre os anos 2017-2019. De forma especifica esta pesquisa buscou caracterizar as mulheres vitimas de violências, segundo características sóciodemográficas, como também caracterizar a violência e o agressor segundo sexo, idade, vinculo ou grau de parentesco com a vitima e consumo ou não de álcool.

\section{MATERIAL E MÉTODOS OU METODOLOGIA (ou equivalente)}

Trata-se de um estudo epidemiológico, descritivo, quantitativo, realizado através de coleta de dados obtidos através da Ficha de Notificação Individual de Violência Interpessoal ou Autoprovocada (Sistema de Informação de Agravos e Notificação SINAN) arquivadas no Serviço de Vigilância Epidemiológica do Hospital Geral Clériston Andrade (HGCA) em Feira de Santana- Bahia, referentes aos atendimentos realizados às mulheres vítimas de violências entre os anos de 2017 a 2018. Não houve cálculo amostral, vez que todos os casos ocorridos neste intervalo de tempo serão incluídos no estudo em questão.

Todas as informações serão transcritas das Fichas de Notificação para o formulário de investigação, serão codificadas e, posteriormente, digitadas em banco de dados e processadas no Programa Estatístico Statistical Package For The Social Science (SPSS) for Windows na versão 19.0. Para controle de qualidade dos dados digitados, processar-seá a revisão periódica dos dados, corrigindo possíveis erros.

\section{RESULTADOS E/OU DISCUSSÃO (ou Análise e discussão dos resultados)}

$\mathrm{Na}$ totalidade foram registrados 277 casos durante o período selecionado, sendo excluídas fichas duplicadas. Destes $100 \%$ foram provenientes do próprio munícipio de Feira de Santana, apresentando como entrada direta a emergência do HGCA, sem registros que as vítimas tenham sido encaminhadas ou assistidas por algum outro setor de saúde.

Para uma análise qualificada do fenômeno complexo da violência e com a finalidade de compreender seus determinantes, que vunerabilizam mulheres a serem 
vítimas, devemos levar em consideração aspectos sociodemográficos como mostra na tabela 1 .

Tabela 1. Características sociodemográficas de mulheres atendidas em uma emergência pública de Feira de Santana, Bahia, nos anos de 2017-2018

\begin{tabular}{lcc}
\hline CARACTERISTICAS & $\mathbf{N}$ & $\%$ \\
\hline Idade & 3 & $1,2 \%$ \\
1 ate 10 anos & 52 & $20,2 \%$ \\
11 a 20 anos & 78 & $30,2 \%$ \\
21 a 30 anos & 74 & $28,7 \%$ \\
31 a 40 anos & 34 & $13,2 \%$ \\
41 a 50 anos & 17 & $6,6 \%$ \\
+50 anos & & \\
Raça/Cor & 12 & $4,8 \%$ \\
Branca & 27 & $10,9 \%$ \\
Preta & 8 & $3,2 \%$ \\
Amarela & 200 & $80,6 \%$ \\
Parda & 1 & $0,4 \%$ \\
Indígena & & \\
Ocupação & 9 & $15,3 \%$ \\
Do lar/dona de caixa & 5 & $8,5 \%$ \\
Empregada doméstica & 6 & $10,2 \%$ \\
Desempregada & 2 & $3,4 \%$ \\
Ambulante & 13 & $22 \%$ \\
Estudante & 6 & $10,2 \%$ \\
Vendedora/caixa & 16 & $27,1 \%$ \\
Outras & 2 & $3,4 \%$ \\
Aposentada & &
\end{tabular}

A motivação da agressão em sua maioria foi desconhecida, tenho como principais causas o sexismo (essa ideia fortalece o poder masculino sobre a mulher, a mulher é parcialmente capaz, tendo como o protagonista no domínio de sua vida o marido) seguido do conflito geracional.

As principais formas de violência relada foram a física (247 casos), psicológica/moral (43 casos), sexual (35casos), colaborando com Silva et al. (2017) que constatou em sua pesquisa física (31.432), seguida da psicológica (19.182), moral (4.627), sexual (3.064) e patrimonial (1.382). A violência contra mulher não se restringe apenas a agressões físicas, mas também a qualquer dano psicológico, moral, patrimonial e sexual, que se manifestem em diversas formas como, mutilações, tortura, privação de liberdade, 
abuso emocional, estrupo, opressão (BANDEIRA, 2014; MYNAYO, 2006), como mostra na tabela 02 , a seguir.

O número de envolvidos foi subestimado, considerando que 157 dos casos apresentaram este campo ignorado, enquanto 107 das vitimas declararam ter um agressor, enquanto 11 destas mulheres apresentaram dois ou mais agressores. Na maioria dos casos as vitimas são violentadas no seu domicilio por seu namorado, cônjuge, ou ex-cônjuge, homens com vinculo parentesco (BANDEIRA, 2014). É alarmante que as fichas não sejam preenchidas de forma adequada, inibindo a dimensão real deste agravo e seus determinantes, como demonstra na tabela abaixo.

Tabela 2. Características da violência contra mulheres atendidas em uma emergência pública de Feira de Santana, Bahia, nos anos de 2017-2018

$\begin{array}{lc}\text { MOTIVAÇÃO DA } & \text { N DE CASOS } \\ \text { LESÃO } & \\ \text { Sexismo } & 13 \\ \text { Homofobia } & 1 \\ \text { Conflito geracional } & 11 \\ \text { Situação de rua } & 9 \\ \text { Desconhecida } & 59 \\ & \\ \text { TIPO DE VIOLÊNCIA } & \\ \text { Fisica } & 247 \\ \text { Psicologica/moral } & 43 \\ \text { Tortura } & 19 \\ \text { Financeira/econômica } & 2 \\ \text { Sexual } & 35 \\ \text { Negligência/abandono } & 1 \\ \text { Intervenção legal } & 1 \\ \text { Outros } & 18 \\ & \end{array}$

Das mulheres vitimas de violência $10,9 \%$ já foram vitimizadas outras vezes, sendo 21,8\% negaram a recorrências destes episódios, $67,3 \%$ destes dados foram ignorados. Em corroboração com Carnevalle et al. (2019); Deslandes (1999); Lucena (2016) a maioria dos casos a violência se repete com igual ou maior intensidade, pois as vitimas apresentam uma dificuldade para sair do ciclo da violência.

Dentre as vitimas de violência 15,9\% foram autoprovocada, convergindo com diversos pesquisadores que avaliam as repercussões das violências nas mulheres, as quais se constituem como uma serie de agravos físicos, dentre elas há repercussões psicológicos 
como depressão, pensamentos suicidas, suicídio, insônia, tristeza profunda, baixa autoestima, medo, ansiedade, e repercussões sociais como isolamento, falta de interação social, introspecção (CARNEIRO et al., 2017; SANTOS; MORÉ, 2011).

\section{CONCLUSÃO}

Esta pesquisa contribui para despertar os profissionais de saúde para a problemática da violência contra mulher, muitas vezes despercebidas, e incentivar a prática de uma atuação que contemple e contabilize a violência nos diagnósticos realizados, aprimorando, assim, a eficácia das ações de saúde, além de assegurar que estas mulheres, vítimas, não sejam re-vitimizadas por estes serviços; ainda colaborar com a formação dos estudantes de graduação em saúde desta universidade ao compreender a atuação da Rede de Atenção ás pessoas vítimas de violência, protocolos e acolhimentos específicos.

Para além disso, destacar um dos limites apresentados por esse estudo que foi a qualidade do preenchimento das informações, quando trata-se se de sistema de informação de saúde, o que acaba por comprometer uma melhor avaliação dos indicadores e uma intervenção de maior resolutividade, estabelecendo medidas de enfrentamento mais eficaz frente à violência, principalmente, a violência de gênero.

\section{REFERENNCIAS}

BANDEIRA, L. M. Violência de gênero: a construção de um campo teórico e de investigação. Revista Sociedade e Estado, São Paulo, v. 29, n. 22, p. 449-469, 2014. Disponível em: http://www.corteidh.or.cr/tablas/r34812.pdf. Acesso em: 08 fev. 2020.

CARNEVALLE, C. V. et al. Notificações de violências contra a mulher adulta no Estado de São Paulo em 2014. Bol. epidemiol. paul., São Paulo, v. 16, n. 181, p. 3-17, 2019. Disponível em: http://docs.bvsalud.org/biblioref/2019/10/1023187/151813-17.pdf. Acesso em: 21 ago. 2020.

DESLANDES, S. F. O atendimento às vítimas de violência na emergência: "prevenção numa hora dessas?” Ciência \& Saúde Coletiva, v. 4, n. 1, p. 81-94, 1999. Disponível em: https://www.scielosp.org/article/csc/1999.v4n1/81-94/. Acesso em: 20 jul. 2020.

LUCENA, K. D. T. de et al. Análise do ciclo da violência doméstica contra a mulher. J Hum Growth Dev., São Paulo, 26, n. 2, p. 1-8, 2016. Disponível em: http://www.revistas.usp.br/jhgd/article/view/119238. Acesso em: 21 ago. 2020

MINAYO, M. C. de S. Parte II- Violência e Saúde Pública: Quadro interpretativo da violência sob a ótica do setor saúde. In: Violência e Saúde Pública. Rio de Janeiro: Fiocruz, 2006. 
SANTOS, A. C. W; MORÉ, C. L. O. O. Repercussão da violência na mulher e suas formas de enfrentamento. Paidéia, Florianópolis, v. 21, n. 49, p. 227-235, 2011. Disponível em: http://www.scielo.br/pdf/paideia/v21n49/10.pdf. Acesso em: 10 mar. 2020.

SILVA, G. M.; LEAO, L. T. de S. O paradoxo da mistura: identidades, desigualdades e percepção de discriminação entre brasileiros pardos. Rev. bras. Ci. Soc., São Paulo, v. 27, n. 80, p. 117-133, 2012. Disponível em: https://www.scielo.br/scielo.php?pid=S010269092012000300007\&script=sci_arttext. Acesso em: 20 jul. 2020. 